\title{
A case report of asymptomatic aortic thrombosis incidentally detected by computed tomography in apparently healthy subject with a history of cancer surgery
}

\author{
Tomonori Sugiura ${ }^{1 *}\left(\mathbb{D}\right.$, Yasuaki Dohi ${ }^{2}$, Sumiyo Yamashita ${ }^{1}$, Shunsuke Murai ${ }^{1}$ and Nobuyuki Ohte ${ }^{1}$
}

\begin{abstract}
Background: Aortic thrombosis is a rare disease and only a few cases of the disease, especially associated with chemotherapy for malignant diseases and/or blood diseases, have been previously reported. Although Virchow's triad for thrombogenesis, namely hypercoagulability, blood flow stasis, and vessel wall injury, is the major factor promoting the formation of thrombosis, the detailed mechanism of the disease has not been well established.

Case presentation: We report a case of aortic thrombosis incidentally detected by computed tomography and then regressed by pharmacotherapy using warfarin. This case is an apparently healthy man in a postoperative state after lung cancer surgery with decreased protein-C activity.

Conclusions: A case of aortic thrombosis without an obvious abnormality of the aorta was incidentally identified. A few cases of aortic thrombosis in healthy aortas have been reported to be associated with chemotherapy or blood diseases, however our present case did not had such a background. Although the detailed mechanism remains to be elucidated, this case suggests that aortic thrombosis can develop in apparently healthy subjects with a history of cancer surgery.
\end{abstract}

Keywords: Aortic thrombosis, Incidental, Computed tomography, Pharmacotherapy

\section{Background}

Aortic thrombosis is a rare disease and only a few cases have been previously reported [1-3]. Malignant diseases and/or blood diseases, such as thrombocytosis and chemotherapy-related hematological disorders, have been identified as one of the causes of aortic thrombosis in these previous reports [1-5]. While Virchow's triad for thrombogenesis, namely hypercoagulability, blood flow stasis, and vessel wall injury, is the major factor accelerating the formation of thrombus in the aortic wall, the detailed mechanism of aortic thrombosis has not

\footnotetext{
* Correspondence: tomosugi@med.nagoya-cu.ac.jp

1 Department of Cardio-Renal Medicine and Hypertension, Nagoya City University Graduate School of Medical Sciences, Kawasumi 1, Mizuho-cho, Mizuho-ku, Nagoya 467-8601, Japan

Full list of author information is available at the end of the article
}

been fully elucidated. Moreover, its therapeutic strategy is still controversial [6].

Previously, we reported a case of multiple aortic thrombosis in a patient with malignant lymphoma complicated by splenic infarction, and successfully treated by non-invasive pharmacotherapy [7]. Since then, we have identified another case of aortic thrombosis which was incidentally detected by computed tomography $(\mathrm{CT})$, when performed for follow-up of primary diseases. Unlike our previous report, the contribution of malignant disease and chemotherapy was not suggested in this case. Here, we report a case of aortic thrombosis with background of surgery for lung cancer 1.5 years ago and no signature of recurrence. 


\section{Case presentation}

A 75-year-old Japanese man who had no history of thrombosis or thromboembolism underwent resection of his right upper lung lobe for adenocarcinoma of localized adenocarcinoma without distant metastasis, 2 years previously. Chemotherapy and radiation therapy were not performed. After the operation, periodic follow-up CT was undertaken every 6 months and fluorodeoxyglucosepositron emission tomography (FDG-PET) was performed after 1 year of operation in order to check for recurrence of lung cancer, and the results showed no recurrence or distant metastasis and no abnormality of the thoracic aorta or unexpected mural thrombus (Fig. 1a). However, an aortic thrombus was incidentally detected in the descending aortic arch 1.5 years after the primary operation (Fig. 1b). At that time, the patient was apparently healthy, with a body temperature of $36.2{ }^{\circ} \mathrm{C}$, blood pressure of $122 / 68 \mathrm{mmHg}$, heart rate of $76 \mathrm{bpm}$, and peripheral oxygen saturation of $96 \%$ in room air. Laboratory data showed slightly elevated D-dimer, decreased plasma protein-C activity, and normal liver function and lipid profile (Table 1). Lupus anticoagulant or anticardiolipin antibody was not detected and the patient stopped smoking at 60-year-old (Brinkman index 800). Although the cause and significance of decreased protein-C activity was not fully understood, we started anticoagulant therapy for aortic thrombosis using warfarin. Follow-up CT showed the aortic thrombus was gradually regressing and was eliminated completely after 6 months of anticoagulant therapy without major complications (Fig. 1c). Then, anticoagulant therapy was terminated without recurrence of aortic thrombus and plasma protein-C activity was recovered within normal range (72\%).

Aortic thrombosis is a rare disease which can cause distal embolism, but can also be detected incidentally in asymptomatic cases [1, 2]. Although aortic mural thrombus associated with abnormal aortic disease, such as aortic aneurysm and aortic dissection, is often seen, a thrombus in an apparently healthy aorta is very rare, since the aortic blood flow is too fast for clotting and the formation of a growing thrombus [1, 2]. Virchow's triad for thrombogenesis, featuring hypercoagulability, blood flow stasis, and vessel wall injury, is known to be important in thrombus formation, however the concept is generally adopted for thrombosis in veins and/or small arteries [6]. On the other hand, thromboembolism complicated with atrial fibrillation is well-known, but arrhythmia cannot be the etiology of local thrombus of the aorta. Thus, the detailed mechanism of the etiology of aortic thrombosis is not well understood $[1,2]$.

In the present report, we describe a case of aortic thrombosis which was seen in an apparently healthy man in a postoperative state after lung cancer surgery with decreased protein- $\mathrm{C}$ activity. Although hereditary protein-C deficiency is well known to be associated with recurrent thrombosis $[8,9]$, this patient and his family

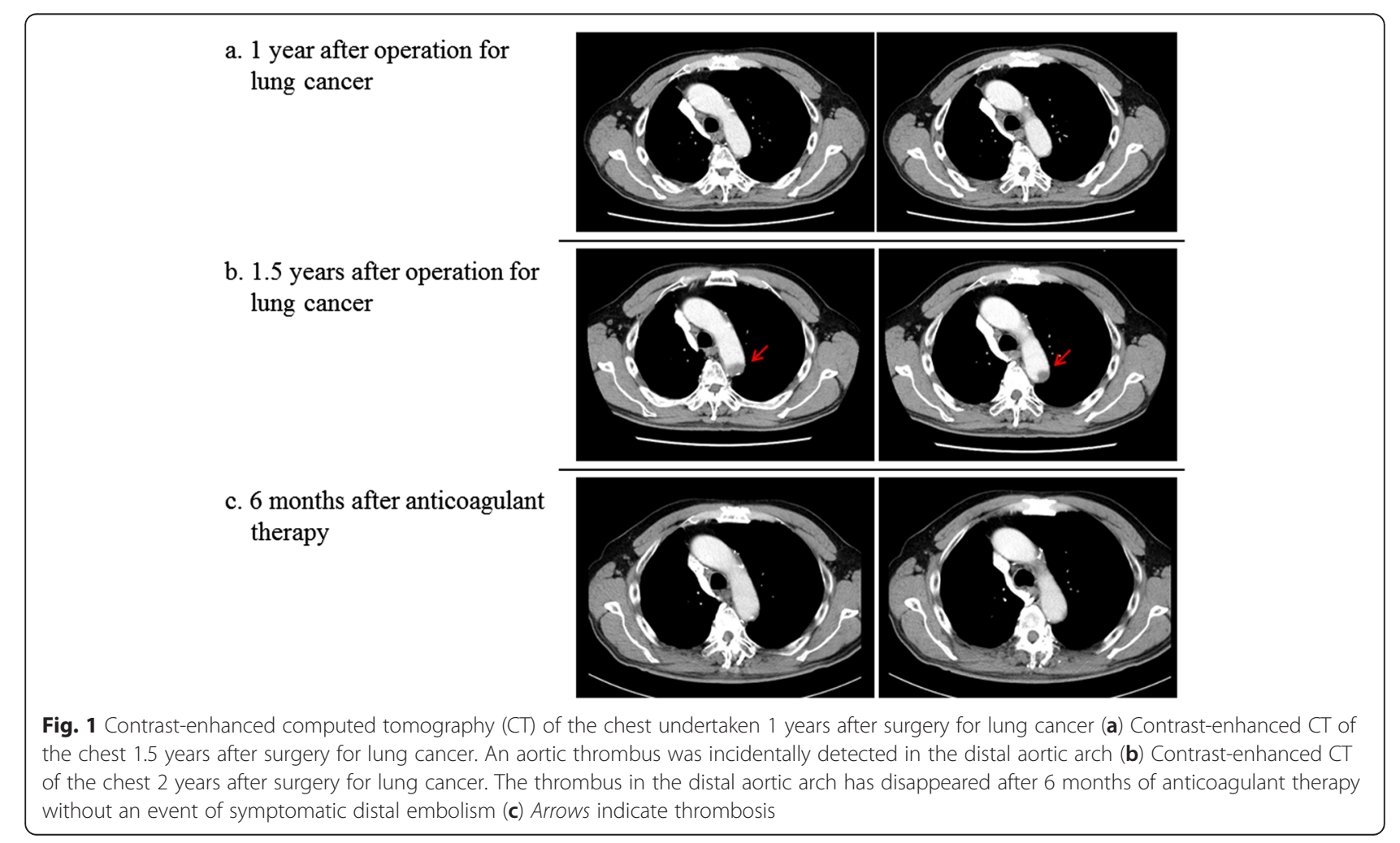


Table 1 Characteristics of the case

\begin{tabular}{|c|c|c|}
\hline Variable & Patient value & Reference range \\
\hline White Blood Cell $(/ \mu \mathrm{L})$ & 5400 & $3600-9600$ \\
\hline Hemoglobin (g/dl) & 14.9 & $13.2-17.2$ \\
\hline Platelet $\left(/ 10^{-4} \mu \mathrm{L}\right)$ & 12.3 & $14.8-33.9$ \\
\hline CK (U/L) & 150 & $62-287$ \\
\hline AST (U/L) & 18 & $13-33$ \\
\hline $\operatorname{ALT}(U / L)$ & 17 & $6-30$ \\
\hline LDH (U/L) & 171 & $119-223$ \\
\hline Creatinine (mg/dl) & 0.89 & $0.60-1.10$ \\
\hline Causal blood glucose (mg/dl) & 107 & $70-139$ \\
\hline Total-cholesterol (mg/dl) & 165 & $128-219$ \\
\hline HDL-cholesterol (mg/dl) & 43 & $40-96$ \\
\hline CRP (mg/dl) & 0.06 & $<0.3$ \\
\hline BNP (pg/ml) & 31.1 & $<18.4$ \\
\hline APTT (\%) & 116.1 & $76.0-130.0$ \\
\hline PT (\%) & 91.6 & $70.0-130.0$ \\
\hline $\mathrm{HbA1c}(\%)$ & 6.1 & $4.6-6.2$ \\
\hline D-dimer $(\mu \mathrm{g} / \mathrm{ml})$ & 1.5 & $<0.5$ \\
\hline Protein C activity (\%) & 45 & $64-146$ \\
\hline Protein C level (\%) & 39 & $70-150$ \\
\hline Total protein S antigen (\%) & 84 & $60-150$ \\
\hline Free Protein S antigen (\%) & 91 & $65-135$ \\
\hline Antithrombin III (mg/dl) & 25.4 & $22.6-33.5$ \\
\hline Lupus anticoagulant (second) & Undetected & - \\
\hline Anticardiolipin antibody & Undetected & - \\
\hline Anticardiolipin $\beta 2 \mathrm{GPI}$ antibodies & Undetected & - \\
\hline
\end{tabular}

CK creatine kinase, AST aspartate aminotransferase, ALT alanine aminotransferase, $L D H$ lactate dehydrogenase, $H D L$ high-density lipoprotein, $C R P C$ reactive protein, $B N P$ brain natriuretic peptide, APTT activated partial thromboplastin time, $P T$ prothrombin time, $\beta 2 G P I \beta 2$ antiglycoprotein I

did not have episodes of thrombosis. Moreover, the protein- $\mathrm{C}$ activity was recovered within normal range after termination of anticoagulant therapy. Protein-C deficiency is often seen in the acute phase of thrombosis and in patients undergoing anticoagulation therapy, since protein-C and protein-S are vitamin K-dependent glycoproteins that are massively lost in such conditions $[8,9]$. Thus, the contribution of protein- $C$ deficiency to the development of aortic thrombosis, while possible, is not clear. Present case is in contrast to several recent reports of aortic thrombosis which were associated with malignant disease, hematological disorders, and chemotherapy-related thrombosis, especially in relation to cisplatin-based chemotherapy $[4,5]$. Actually, the background of our previously reported case of aortic thrombosis included malignant lymphoma and related chemotherapy [6].

The therapeutic strategy for aortic thrombosis is controversial, however, the main strategy is conservative pharmacotherapy [1-3]. There is no definitive evidence as to the antithrombotic therapy to be selected or the appropriate duration of such treatment in the case of aortic thrombosis. Therefore, we chose warfarin therapy for 6 months in accordance with the standard therapy in the case of venous thrombosis. After termination of the warfarin therapy, the recurrence of aortic thrombosis has not been confirmed more than 6 months. Another strategy is surgical therapy, which is particularly useful for symptomatic cases with distal thromboembolism, and combined therapy may also be selected occasionally [1-3]. We selected conservative pharmacotherapy since signs of distal thromboembolism were not evident. However, recently the technique of aortic stent graft treatment has been dramatically improved, allowing an alternative treatment choice for aortic thrombosis, especially in emergency cases or in unfavorable conditions [10].

\section{Conclusions}

We identified a case of aortic thrombosis without an abnormality of the aorta. A few cases of aortic thrombosis in healthy aortas have been reported to be associated with chemotherapy or blood diseases, however our present case did not have such a background. Although the detailed mechanism remains to be elucidated, this case suggest that aortic thrombosis can develop in apparently healthy subjects with a history of cancer surgery.

\section{Abbreviations}

APTE, acute pulmonary thromboembolism; $C$, computed tomography; FDG-PET, fluorodeoxyglucose-positron emission tomography

\section{Acknowledgements}

None.

Funding

Not applicable.

Availability of data and materials

Not applicable.

\section{Authors' contribution}

TS, did bedside work and prepared the manuscript. YD, discussed the case, modified manuscript. SY, did bedside work. SM, did bedside work. NO, discussed the case, modified the manuscript. All authors read and approved the final manuscript.

\section{Competing interest}

The authors declare that they have no competing interests.

\section{Consent for publication}

Written informed consent was obtained from the patient for publication of this case report and any accompanying images. A copy of the written consent is available for review by the Editor-in-Chief of this journal.

Ethics approval and consent to participate Not applicable. 


\section{Author details}

'Department of Cardio-Renal Medicine and Hypertension, Nagoya City University Graduate School of Medical Sciences, Kawasumi 1, Mizuho-cho, Mizuho-ku, Nagoya 467-8601, Japan. ²Department of Internal Medicine,

Faculty of Rehabilitation Science, Nagoya Gakuin University, Nagoya, Japan.

Received: 15 June 2016 Accepted: 29 July 2016

Published online: 02 August 2016

\section{References}

1. Sohn V, Arthurs Z, Andersen C, Starnes B. Aortic thrombus due to essential thrombocytosis: strategies for medical and surgical management. Ann Vasc Surg. 2008;22:676-80.

2. Fayad ZY, Semaan E, Fahoum B, Briggs M, Tortolani A, D'Ayala M. Aortic mural thrombus in the normal or minimally atherosclerotic aorta. Ann Vasc Surg. 2013;27:282-90.

3. Geha AS, El-Zein C, Massad MG, Bagai J, Khoury F, Evans A, Kpodonu J. Surgery for aortic arch thrombosis. Thorac Cardiovasc Surg. 2004;52:187-90.

4. Hahn SJ, Oh JY, Kim JS, Kim DY. A case of acute aortic thrombosis after cisplatin-based chemotherapy. Int J Clin Oncol. 2011;16:732-6.

5. Ito S, Nakamura Y, Noumi T, Sasaki Y. Acute aortic thrombosis during cisplatin based chemotherapy for gastric cancer. Intern Med. 2013:52:973-5.

6. Wolberg AS, Aleman MM, Leiderman K, Machlus KR. Procoagulant activity in hemostasis and thrombosis: Virchow's triad revisited. Anesth Analg. 2012; 114:275-85.

7. Hachiya K, Sugiura T, Dohi Y, Ohte N. Multiple aortic thrombosis successfully treated using pharmacotherapy. Intern Med. 2013;52:2155-6.

8. Onwuanyi A, Sachdeva R, Hamirani K, Islam M, Parris R. Multiple aortic thrombi associated with protein $\mathrm{C}$ and $\mathrm{S}$ deficiency. Mayo Clin Proc. 2001;76:319-22.

9. Wypasek E, Undas A. Protein C and protein S deficiency - practical diagnostic issues. Adv Clin Exp Med. 2013;22:459-67.

10. Verma H, Meda N, Vora S, George RK, Tripathi RK. Contemporary management of symptomatic primary aortic mural thrombus. J Vasc Surg. 2014;60:1524-34.

\section{Submit your next manuscript to BioMed Central} and we will help you at every step:

- We accept pre-submission inquiries

- Our selector tool helps you to find the most relevant journal

- We provide round the clock customer support

- Convenient online submission

- Thorough peer review

- Inclusion in PubMed and all major indexing services

- Maximum visibility for your research

Submit your manuscript at www.biomedcentral.com/submit 